\title{
Electrochemical impedimetric biosensor based on a nanostructured polycarbonate substrate
}

\author{
This article was published in the following Dove Press journal: \\ International Journal of Nanomedicine \\ 5 January 2012 \\ Number of times this article has been viewed
}

\author{
Yu-Shan Chen' \\ Chia-Che $\mathrm{Wu}^{\mathrm{I}}$ \\ Jaw-Ji Tsai ${ }^{2}$ \\ Gou-Jen Wang ${ }^{1,3}$ \\ 'Department of Mechanical \\ Engineering, National Chung-Hsing \\ University, ${ }^{2}$ Department of Medical \\ Education and Research, Taichung \\ Veterans General Hospital, ${ }^{3} \mathrm{Graduate}$ \\ Institute of Biomedical Engineering, \\ National Chung-Hsing University, \\ Taichung, Taiwan
}

\begin{abstract}
This study integrates the techniques of nanoelectroforming, hot-embossing, and electrochemical deposition to develop a disposable, low-cost, and high sensitivity nanostructure biosensor. A modified anodic aluminum oxide barrier-layer surface was used as the template for thin nickel film deposition. After etching the anodic aluminum oxide template off, a three-dimensional mold of the concave nanostructure array was created. The fabricated threedimensional nickel mold was further used for replica molding of a nanostructure polycarbonate substrate by hot-embossing. A thin gold film was then sputtered onto the polycarbonate substrate to form the electrode, followed by deposition of an orderly and uniform gold nanoparticle layer on the three-dimensional gold electrode using electrochemical deposition. Finally, silver nanoparticles were deposited on the uniformly deposited gold nanoparticles to enhance the conductivity of the sensor. Electrochemical impedance spectroscopy analysis was then used to detect the concentration of the target element. The sensitivity of the proposed scheme on the detection of the dust mite antigen, Der $\mathrm{p} 2$, reached $0.1 \mathrm{pg} / \mathrm{mL}$.
\end{abstract}

Keywords: nanoelectroforming, nanostructure polycarbonate substrate, gold nanoparticles, silver nanoparticles, electrochemical impedance spectroscopy

\section{Introduction}

The current trend for point-of-care device development requires that a device be low-cost, sensitive, specific, easy to use, rapid and robust, and disposable, as well as having a small sample requirement. This is especially the case for people who live in developing countries, where even common tests are not affordable and fundamental infrastructure is often not available. ${ }^{1-3}$ A variety of microfluidic devices such as the micro total analysis system ( $\mu$ TAS) have been developed which partially meet these demands. ${ }^{4-7}$ However, the requirement of lithographic equipment and the relatively high cost of such devices can place limitations on mass production and general applications.

Microfluidic paper-based analytical devices ( $\mu$ PADs) as initially proposed by Martinez et al can be good alternatives to satisfy the low cost and ease of use requirements of modern point-of-care diagnostic devices. ${ }^{8-10}$ A $\mu \mathrm{PAD}$ generally consists of a paper-based microfluidic testing platform based on patterned channels upon hydrophilic paper delimited by partitions of hydrophobic material and a light reflectance detector for quantitative colorimetric detection of target analytes at the test zone. Methods for paper patterning include photolithography, ${ }^{8,11}$ plotter printing of polydimethylsiloxane patterns in paper, ${ }^{12}$ inkjet printing, ${ }^{13,14}$ and wax printing. ${ }^{15,16}$ A simple reflectance detection device such as a desktop scanner or a digital camera 
is quite adequate for use with a $\mu \mathrm{PAD}$. Other detection methods, such as quantitative fluorescence and absorbance measurements obtained using a microplate reader, ${ }^{17}$ electrochemistry, ${ }^{18-20}$ or electrochemiluminescence, ${ }^{21}$ can also be implemented for the quantitative detection of the target analytes. The $\mu$ PADs, although still in their infancy, have proven to be a promising solution for simple and low-cost quantitative detection of biological and inorganic species in aqueous solutions. However, their relatively low sensitivity may limit their applications for the detection of rare molecules. It is of substantial interest to develop a highly sensitive and low-cost biosensor for precise detection of low levels of species in biological samples, including bodily fluids.

Electrochemical impedance spectroscopy detection involving a label-free process has enabled simplification of the detection and enhancement of the sensitivity of measurement. ${ }^{22-25}$ Gold nanoparticles, which can provide substantial biocompatibility with biomolecules and a stable immobilization of biomolecules that retain their bioactivity, have made them a very attractive material as electrodes of impedimetric biosensors. ${ }^{26,27}$

This study demonstrates the integration of nanoelectroforming, hot-embossing, and electrochemical deposition techniques for the fabrication of a low-cost polycarbonatebased biosensor platform. The key component in this polycarbonate-based platform is a gold nanoparticle-deposited nanostructured polycarbonate substrate which serves as the transducer for detection of target analytes by binding to it. The nanostructure polycarbonate substrates can be replicated using a nickel mold by means of nano hot-embossing or nano injection molding. This makes the platform disposable and low-cost. In addition, the high surface to volume ratio of the nanostructured polycarbonate substrate and uniformly deposited gold nanoparticles allow the attachment of many more analytes to the transducer which, in turn, means considerable enhancement of sensitivity. In this study, detection of the dust mite antigen, Der $\mathrm{p} 2$, is carried out using electrochemical impedance spectroscopy analysis to demonstrate the performance of the proposed polycarbonatebased biosensor scheme.

\section{Materials and methods}

\section{Fabrication of a polycarbonate-based transducer}

Figure 1 is a schematic illustration of the proposed polycarbonate-based biosensor design. It consists of a polycarbonate substrate with a nanohemisphere array,

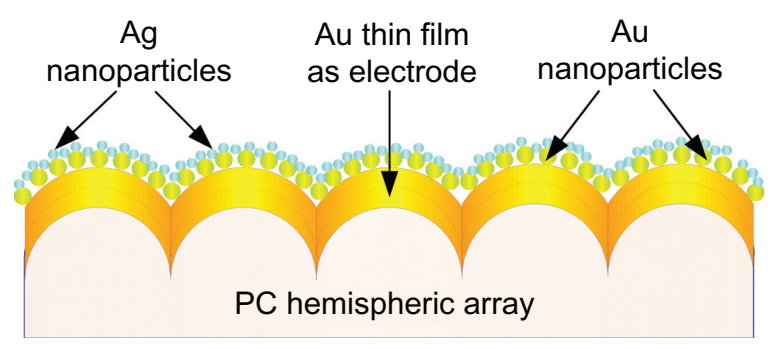

Figure I Schematic illustration of the proposed polycarbonate-based biosensor.

a gold thin film sputtered on the polycarbonate substrate to form the electrode, gold nanoparticles uniformly deposited on the film, and smaller silver nanoparticles deposited on the gold nanoparticles. The sequential fabrication processes included fabrication of a nanostructured polycarbonate substrate, deposition of a thin gold film, annealing, electrochemical deposition of gold nanoparticles, and electrochemical deposition of silver nanoparticles.

\section{Fabrication of a nanostructured polycarbonate substrate}

The nanostructured polycarbonate substrate was hotembossed using a nickel replica mold. The fabrication procedures of the nano replica mold are briefly described in Figure 2. A modified anodic aluminum oxide barrier-layer surface was used as the master mold for nickel thin film deposition. After etching off the anodic aluminum oxide template, a three-dimensional replica of the concave nanostructure array could be obtained.

The nanostructured polycarbonate substrates were produced by Leadoptical Co, Ltd, (Taichung, Taiwan), a company specializing in microlens array fabrication. Because the glass transition temperature $\left(T_{\mathrm{g}}\right)$ of the polycarbonate used was $120^{\circ} \mathrm{C}$, the embossing temperature was set at $150^{\circ} \mathrm{C}$. After holding for 50 seconds, a cooling process at $100^{\circ} \mathrm{C}$ for 180 seconds was carried out.

\section{Deposition of a thin gold film}

A thin gold film electrode was deposited on the hemispheric array of the polycarbonate substrate using radiofrequency magnetron sputtering. The deposition was conducted under a

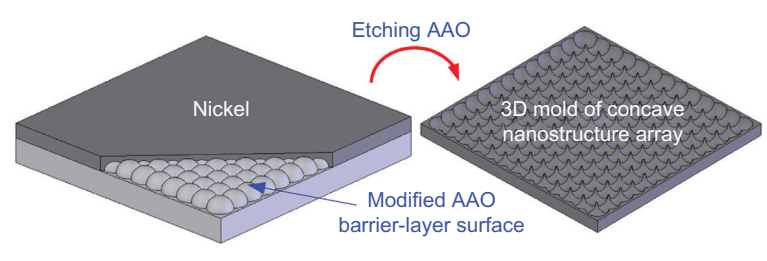

Figure 2 Fabrication procedures for the nano replica mold. 
$4.0 \times 10^{-3}$ Torr pressure at room temperature with a $20 \mathrm{sccm}$ $(0.254$ Torr $\times 1 /$ second $)$ argon injection and $80 \mathrm{~W}$ power lasting for 1.5 minutes. This created a $30 \mathrm{~nm}$ thin gold film.

\section{Annealing}

An annealing process was employed to refine further the surface structure of the thin gold film electrode and make it homogeneous. Sequential annealing procedures included heating the sample to $120^{\circ} \mathrm{C}$ at a rate of $5^{\circ} \mathrm{C} /$ minute, maintaining that temperature for 60 minutes, followed by cooling the sample in open air to room temperature.

\section{Packaging}

To ensure the uniformity of the sensing area and prevent other solutions from coming into contact with the sample, precise packaging before electrochemical depositing of gold nanoparticles was needed. The packaging procedures are described as follows: prepare a $2.5 \times 2.5 \mathrm{~cm}^{2}$ square parafilm; make a $\phi=6 \mathrm{~mm}$ hole in the center of the parafilm; daub a thin layer of epoxy on the bottom surface of the parafilm square, followed by bonding of the parafilm to the gold film deposited polycarbonate substrate to enclose the sensing area of the device; and package the device using silica gel to ensure air tightness.

\section{Deposition of gold nanoparticles}

The electrochemical deposition was processed by an SP-150 electrochemical analyzer (EC-Lab, Knoxville, TX). The packaged sample was placed at the working electrode, with the thin gold film serving as the electrode. The counter electrode and the reference electrode were a platinum film and an $\mathrm{Ag} / \mathrm{AgCl}$ electrode, respectively. The deposition processes are described below.

The electrolyte was prepared by dissolving $1 \mathrm{~mL}$ of $0.02 \mathrm{M} \mathrm{HAuCl}_{4}$ (Sigma Aldrich, St Louis, MO) solution in $39 \mathrm{~mL}$ of deionized water. The cyclic voltammetric method was performed using the SP-150 to examine the reduction potential of the $\mathrm{HAuCl}_{4}$ solution. The scanning range was set to be between $-0.8 \mathrm{~V}$ and $+0.8 \mathrm{~V}$. Three reducing peaks, at $0.8 \mathrm{~V},-0.2 \mathrm{~V}$, and $-0.8 \mathrm{~V}$, respectively, were detected, where $-0.8 \mathrm{~V}$ denoted the reducing peak of a monovalent gold ion. Several experiments with reducing potentials set around $-0.8 \mathrm{~V}$ were conducted. The results indicated that $-0.7 \mathrm{~V}$ was a more suitable reducing potential for the $\mathrm{HAuCl}_{4}$ solution used in this study.

The electrochemical deposition was processed under a DC $-0.7 \mathrm{~V}$ electric potential at room temperature, lasting for 180 seconds. Several experiments with different deposition durations were carried out. It was found that 180 seconds could achieve better deposition of gold nanoparticles.

\section{Deposition of silver nanoparticles}

Due to its high electric and thermal conductivity, silver has been widely used in micro/nano systems to enhance conductivity. In this study, silver nanoparticle gel was prepared using the Lee and Meisel method. ${ }^{28}$ Silver nanoparticles were then electrochemically deposited on the gold nanoparticles to increase further the conductivity of the device. The deposition processes are described below.

A $25 \mathrm{~mL}$ solution of $1 \mathrm{mM} \mathrm{AgNO}_{3}$ was added to a $1 \mathrm{mM}$ ice-cold $\mathrm{NaBH}_{4}(75 \mathrm{~mL})$. A canary yellow silver nanoparticle gel was synthesized by stirring the mixture at $40^{\circ} \mathrm{C}$ for 2 minutes. Excess $\mathrm{BH}_{4}^{-}$can be a capping agent for silver nanoparticles. Continuous stirring for 1 hour was essential to prevent aggregation of the silver nanoparticles.

The reducing potential for better reduction of silver ions was detected to be $-0.4 \mathrm{~V}$ using cyclic voltammetric procedures, ie, the same as for measurement of the reducing potential for the $\mathrm{HAuCl}_{4}$ solution. Electrochemical deposition of the silver nanoparticles was achieved by application of a $\mathrm{DC}-0.4 \mathrm{~V}$ electric potential for 150 seconds at room temperature.

\section{Electrochemical characterization}

The SP-150 electrochemical analyzer used for nanoparticle deposition was also employed for cyclic voltammetry testing. A platinum wire and an $\mathrm{Ag} / \mathrm{AgCl}$ electrode were used as the counter and reference electrodes, respectively. The active surface area was estimated with steady-state voltammetry using a $0.5 \mathrm{M} \mathrm{H}_{2} \mathrm{SO}_{4}$ solution as the supporting electrolyte. The cyclic voltammogram trace could be used to calculate the actual area of the sensing device which is most effective for adhesion of analytes. ${ }^{29}$

\section{Testing sample preparation}

Allergic rhinitis and asthma are the most often observed allergic symptoms of the respiratory system. House dust mites are known to be a common cause of asthma and allergic reactions worldwide. It has been reported that the group 2 allergen, Der p2, can activate innate tolllike receptor on respiratory epithelial cells to aggravate respiratory diseases. ${ }^{30}$ In this study, Der p2 was used for evaluation of the proposed polycarbonate-based biosensor. Der $\mathrm{p} 2$ is prepared using the procedures proposed by Tsai et al. ${ }^{31}$ The self-assembled monolayer method is adopted for immobilization of Der p2 on the sensor. 
The procedures for the self-assembled monolayer are briefly described below.

First, the surface of the sensor was cleaned by sequentially soaking it in ethanol, acetone, and deionized water, and then vibrating it using ultrasonic waves for 5 minutes. $10 \mu \mathrm{L}$ of a 10 mM 11-mercaptoundecanoic acid (11-MUA) solution was then dispensed onto the sensor surface to construct a 11-MUA self-assembled monolayer anchor membrane. A $20 \mu \mathrm{L}$ sample of the mixed NHS (N-hydroxysuccinimide) and EDC (1-ethyl-3-[3-dimethyl-aminopropyl]-carbodiimide) solution (molar ratio, 1:2) was further allotted to the sensor for 10 minutes to activate carboxylic groups on the 11-MUA membrane. After two washings with phosphate-buffered solution, the sensor was bathed in a $20 \mu \mathrm{L}(10 \mu \mathrm{g} / \mathrm{mL})$ dust mite monoclonal antibody ( $\mathrm{IgG})$ solution and then incubated for 10 minutes. The IgG supplied by Bethyl Laboratories Inc, (Montgomery, TX) was a dust mite monoclonal antibody and could only bind to the dust mite antigen, Der p2. ${ }^{31}$ The $\mathrm{NH}_{2}^{+}$group in IgG was substituted for the NHS functional group and chemically bound with the $\mathrm{COOH}^{-}$group on the MUA membrane. The sensor was again rinsed twice with a phosphate buffer solution ( $\mathrm{pH}$ 7.4). To ensure binding

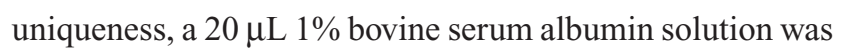
used as the blocking layer to seal off the binding sites of those IgG molecules which did not bond with the MUA membrane. Finally, sensing samples were acquired by dipping the sensor into Der $\mathrm{p} 2$ solutions of different concentrations $(10 \mathrm{ng} / \mathrm{mL}$, $1 \mathrm{ng} / \mathrm{mL}, 0.1 \mathrm{ng} / \mathrm{mL}, 0.01 \mathrm{ng} / \mathrm{mL}, 1 \mathrm{pg} / \mathrm{mL}$, and $0.1 \mathrm{pg} / \mathrm{mL}$ ) at $4^{\circ} \mathrm{C}$ for 30 minutes.

\section{Electrochemical impedance spectroscopy}

Electrochemical impedance spectroscopic analysis is a method commonly used for determining information about an interface. The impedance information of the system can be evaluated by applying a periodic AC signal of small amplitude to the interface and detecting the actual system response. In this study, this method of analysis was implemented for the detection of the Der $\mathrm{p} 2$ concentration in different solutions. The SP-150 electrochemical analyzer was also used for electrochemical impedance spectroscopy analysis.

The polycarbonate-based biosensor, platinum film, and $\mathrm{Ag} / \mathrm{AgCl}$ serve as the working electrode, counter electrode, and reference electrode, respectively, for electrochemical impedance spectroscopy. The buffer solution is a mixture of $5 \mathrm{mM} \mathrm{Fe}(\mathrm{CN})_{6}{ }^{4-}$ and $5 \mathrm{mM} \mathrm{Fe}(\mathrm{CN})_{6}{ }^{3-}$ in $100 \mathrm{mM}$ 2-(N-morpholino) ethanesulfonic acid $(\mathrm{pH}=6.0)$. The applied $\mathrm{DC}$ power and $\mathrm{AC}$ power are $0 \mathrm{~V}$ and $5 \mathrm{mV}$, respectively. The AC frequency ranges from $50 \mathrm{mHz}$ to $50 \mathrm{kHz}$.

\section{Results and discussion}

\section{Transducer fabrication}

Figure 3 shows images of the hot-embossed polycarbonatebased substrates. From the scanning electron microscopic image, it was observed that high-order nanohemispheres with a diameter of around $80 \mathrm{~nm}$ could be transferred from the nickel replica mold to the polycarbonate material. In replica molding or imprinting, robustness and durability of the replica mold are highly desired for mass production applications. The nickel replica mold fabricated using the anodic aluminum oxide barrier/nickel thin film deposition process enabled repetitive and durable production of polycarbonate substrates with a nanohemisphere array.

Figure 4 shows a scanning electron microscopic image of a gold nanoparticle-deposited electrode. The uniformly and compactly deposited gold nanoparticles had an average diameter of around $30 \pm 3 \mathrm{~nm}$ on scanning electron microscopic images using a commercial software Image-Pro Plus (Media Cybernetics, Bethesda, MD). The uniformly propagated electric flux perpendicular to the hemispheric thin gold film electrode attracted the positive charges of the gold
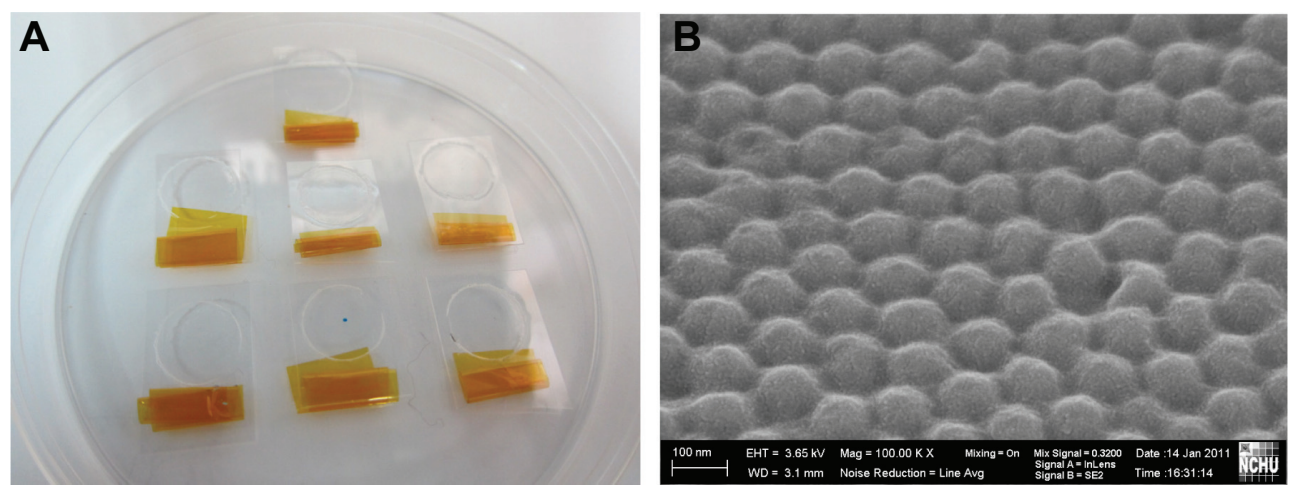

Figure 3 Images of a polycarbonate nanohemisphere array created using hot-embossing; (A) real products; (B) Scanning electron microscopic image. 


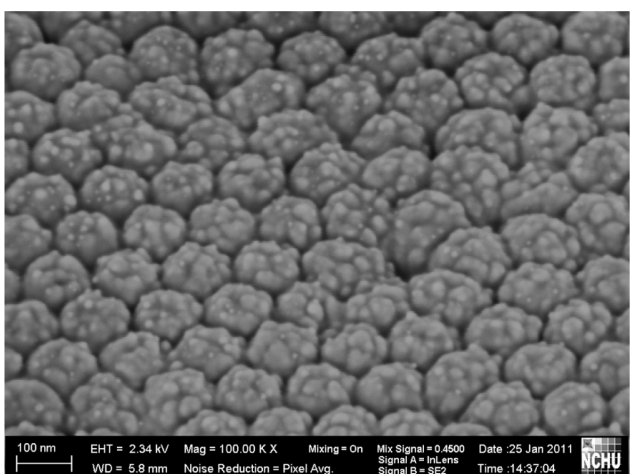

Figure 4 Scanning electron microscopic image of gold nanoparticles synthesized by electrochemical deposition.

nanoparticles in the electrolyte. It was revealed that the gold nanoparticles could be densely deposited onto the surface of the thin gold film electrode without adding a reducing agent or stabilizer.

Because the silver nanoparticles were used for conductivity enhancement, only a small amount of them were deposited on the gold nanoparticle-deposited electrode. A silver content of $0.3 \%$ was detected using a chemical analysis and electron spectroscopy (PHI 5000; ULVAC-PHI Inc, Kanagawa, Japan).

\section{Electrochemical characterization}

Figure 5 shows the steady-state cyclic voltammetry and I-t curves transformed from cyclic voltammetry for the nanostructured thin gold film before gold nanoparticle deposition and the gold nanoparticle deposited electrodes in $0.5 \mathrm{M} \mathrm{H}_{2} \mathrm{SO}_{4}$ at $100 \mathrm{mV} / \mathrm{s}$ versus that of the $\mathrm{Ag} / \mathrm{AgCl}$ reference electrode. The total amount of electric charge in each electrode could be estimated by integrating the area of the reducing peak in Figure 5B. The total amount of electric charges of the film before gold nanoparticle deposition and the polycarbonate/gold/gold nanoparticle electrode were estimated to be $16.51 \mu \mathrm{C}$ and $53.90 \mu \mathrm{C}$, respectively. Since the charge required to form $\mathrm{AuO}$ per $\mathrm{cm}^{2}$ of gold electrode is $386 \mu \mathrm{C}$, the effective areas of the thin gold film before gold nanoparticle nanostructure deposition and the polycarbonate/ gold/gold nanoparticle electrode were calculated to be 0.043 $(16.51 \mu \mathrm{C} / 386 \mu \mathrm{C})$ and $0.14(53.90 \mu \mathrm{C} / 386 \mu \mathrm{C}) \mathrm{cm}^{2}$, respectively. The effective area was enhanced 3.26-fold due to the deposition of gold nanoparticles.

\section{Electrochemical impedance spectroscopy}

The electrochemical impedance spectroscopy analysis results obtained using an SP-150 electrochemical analyzer are presented in Figure 6. Figure 6A shows the Nyquist plots for a gold nanoparticle-deposited electrode, an electrode after the anti-dust mite monoclonal IgG was bound to the NHS-EDC, and electrodes after the Der p2 (with various concentrations) were immobilized for the anti-dust mite monoclonal IgG. The diameter of each individual semicircular electrochemical impedance spectroscopy curve in Figure 6A represents the charge transfer resistance of the electrode with respect to this specific analysis. Figure 6A reveals that the charge transfer resistance for each individual electrode increased with an increase in Der $\mathrm{p} 2$ concentration. In other words, the impedance of the Der $\mathrm{p} 2$ binding device increased with an increase in Der p2 concentration. The electrochemical impedance spectroscopy results could be modeled by the Randles' equivalent circuit shown in the inset to Figure 6A.

Total impedance in the Randles' equivalent circuit is composed of the electrolyte resistance $\left(R_{s}\right)$, the charge transfer resistance $\left(R_{e t}\right)$, and the double layer capacitance $\left(C_{d l}\right)$. Since $R_{s}$ represents the bulk properties of the electrolyte solution, it is unrelated to the chemical reactions coming about at the
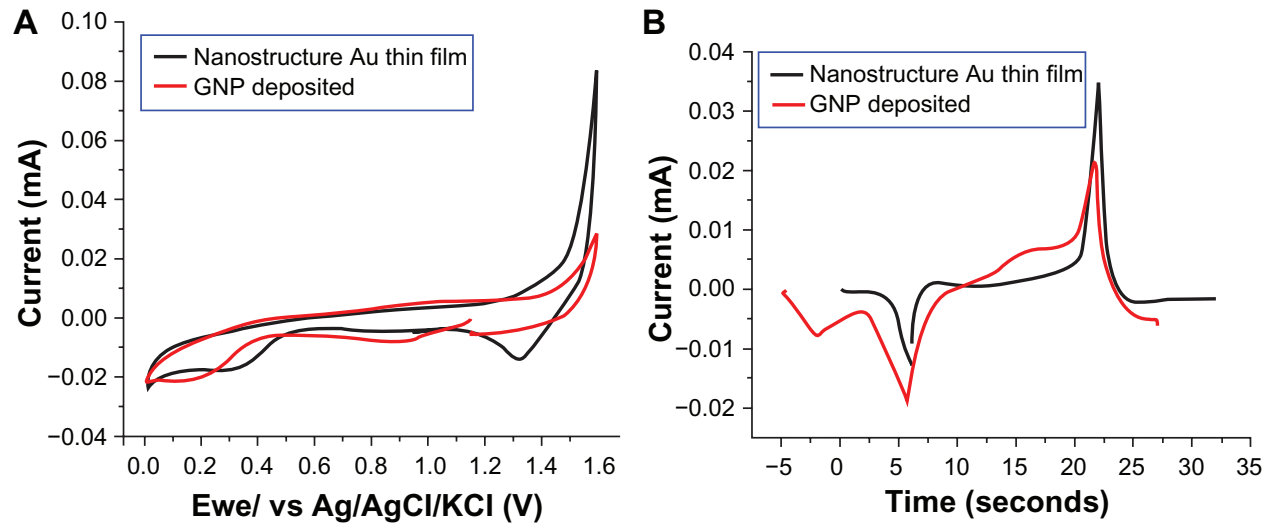

Figure 5 Cyclic voltammetry and I-t curves transformed from the cyclic voltammetry for the film before deposition of the nanostructure thin gold film and the gold nanoparticle-deposited electrodes. 

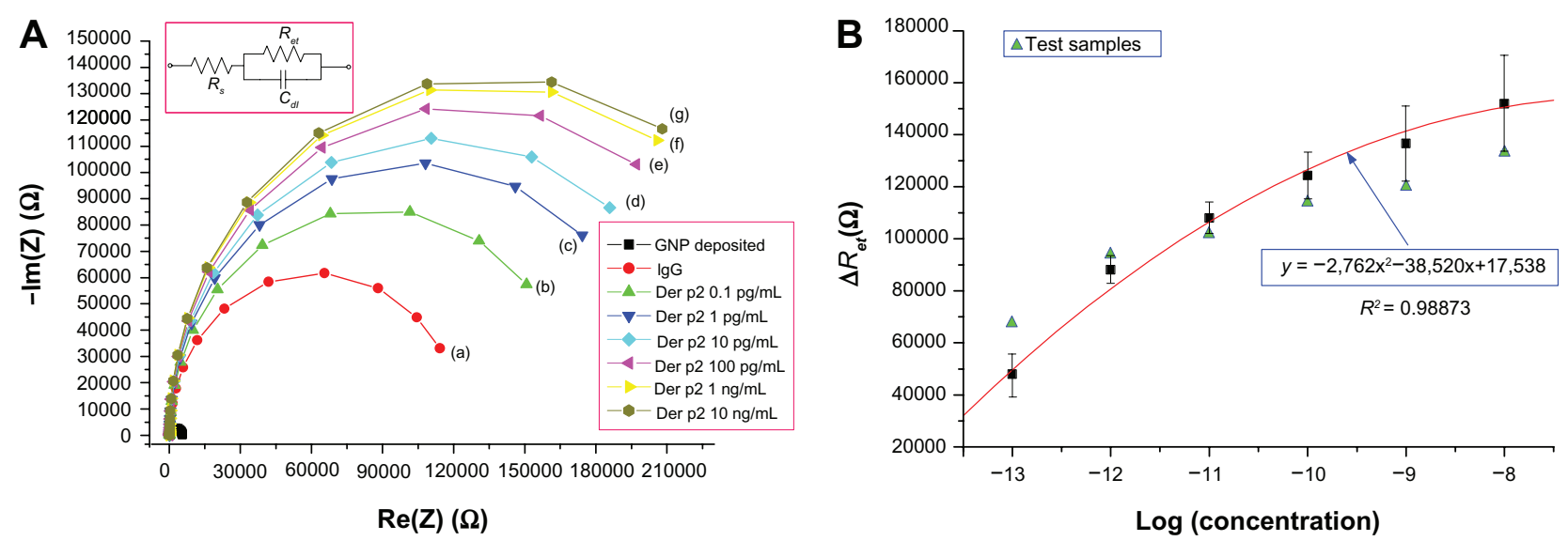

Figure 6 Electrochemical impedance spectroscopy results: (A) Impedance plots for Der $\mathrm{p} 2$ at various concentrations: (a) $1 \mathrm{gG}$, (b) $10^{-13} \mathrm{~g} / \mathrm{mL}$, (c) $10^{-12} \mathrm{~g} / \mathrm{mL},(\mathbf{d}) 10^{-11} \mathrm{~g} / \mathrm{mL}$, (e) $10^{-10} \mathrm{~g} / \mathrm{mL}$, (f) $10^{-9} \mathrm{~g} / \mathrm{mL},(\mathrm{g}) 10^{-8} \mathrm{~g} / \mathrm{mL}$; (B) $\Delta R_{\text {et }}$ as a function of the logarithmic concentration of Der $\mathrm{p} 2$ for the proposed polycarbonate-based biosensor.

electrode interface. The values of $R_{e t}$ and $C_{d l}$ change with the substance bonded onto the electrode surface. Table 1 presents the fitting parameters for the equivalent circuit model of the polycarbonate-based biosensor corresponding to the Nyquist plots in Figure 6A, in which $\Delta R_{e t}$ denotes the different levels of resistance between the electrode in the individual selfassembled monolayer stage and the $\mathrm{IgG}$ bonding electrode. As tabulated in Table 1, the value of each $R_{s}$ is much smaller, and can be neglected when compared with its corresponding $R_{e t}$ value. Hence, the Randles' equivalent circuit can be simplified as follows:

$$
\begin{aligned}
Z(\omega) & =\frac{R_{e t}}{1+\omega^{2} R_{e t}{ }^{2} C_{d l}{ }^{2}}-j \frac{\omega R_{e t}{ }^{2} C_{d l}}{1+\omega^{2} R_{e t}{ }^{2} C_{d l}{ }^{2}} \\
& =R+j X
\end{aligned}
$$

As expressed in Eq (1), both $R_{e t}$ and $C_{d l}$ affect the impedance plot. However, Table 1 shows that the difference in $R_{e t}$ between the electrode for the individual self-assembled monolayer stage and the gold nanoparticle-deposited electrode is more substantial when compared with the change in $C_{d l}$. Hence, $\Delta R_{e t}$ can be used as the parameter to relate the sensor response to different analyte concentrations.

Figure 6B shows $\Delta R_{e t}$ as a function of the logarithmic concentration of Der $\mathrm{p} 2$ for the proposed polycarbonate-based nanobiosensor. For each concentration, three experiments were conducted. All the standard deviations for different concentrations are illustrated by the error bar. The sensor response is fitted by a conic section with $R^{2}=0.98873$. The detection limit was around $0.1 \mathrm{pg} / \mathrm{mL}$, as indicated by curve a in Figure 6A. A dynamic range of up to $10 \mathrm{ng} / \mathrm{mL}$ (curve $\mathrm{g}$ in Figure 6A) is also presented. When the $\Delta R_{e t}$ of a desired Der $\mathrm{p} 2$ solution was detected, the concentration of Der p2 could be determined by this standard regression curve. Test samples for each concentration were prepared for further verification. It was observed that the variations in the test samples were smaller in the concentration range between $10^{-12} \mathrm{~g} / \mathrm{mL}$ and $10^{-10} \mathrm{~g} / \mathrm{mL}$.

It is presumed that the uniformly distributed gold nanoparticles on the hemispheric array increased the surface area of the electrode so that an increased number of MUA molecules could attach to the electrode; therefore, the sequential binding of EDC/NHS molecules and IgG molecules was thus increased. Hence, the effective binding between Der $\mathrm{p} 2$ and $\operatorname{IgG}$ could be enhanced. As a result, the sensitivity of the sensor was considerably enhanced. This proposed low-cost and high sensitivity polycarbonate-based nanobiosensor could be useful for the rapid detection of rare molecules in an analyte.

Table I Fitting parameters for the Randles' equivalent circuit

\begin{tabular}{lllllllll}
\hline & GNP & IgG & $\mathbf{0 . 1} \mathbf{~ p g}$ & $\mathbf{I ~ p g}$ & $\mathbf{1 0} \mathbf{~ p g}$ & $\mathbf{1 0 0} \mathbf{~ p g}$ & $\mathbf{I ~} \mathbf{~ g}$ & $\mathbf{1 0} \mathbf{~ n g}$ \\
\hline$R_{\text {et }}\left(10^{5} \Omega\right)$ & 0.053 & 1.24 & 1.73 & 2.07 & 2.26 & 2.51 & 2.67 & 2.73 \\
$R_{s}(\Omega)$ & 184.7 & 181.1 & 177.9 & 179.4 & 181.3 & 181.1 & 181.2 & 180.1 \\
$C_{d l}\left(10^{-6} \mathrm{~F}\right)$ & 3.95 & 3.73 & 3.51 & 3.35 & 3.38 & 3.31 & 3.24 & 3.26 \\
$\Delta R_{\text {et }}\left(10^{5} \Omega\right)$ & & & 0.49 & 0.84 & 1.03 & 1.27 & 1.43 & 1.50 \\
\hline
\end{tabular}

Abbreviation: GNP, gold nanoparticle. 


\section{Conclusion}

In this study, we designed a low-cost and highly sensitive polycarbonate-based nanostructured biosensor. The sequential synthesis processes of the biosensor included fabrication of a nanostructured polycarbonate substrate, deposition of a thin gold film, annealing, electrochemical deposition of gold nanoparticles, and electrochemical deposition of silver nanoparticles. The sensing limit and dynamic range of the proposed design for Der $\mathrm{p} 2$ detection were investigated using electrochemical impedance spectroscopy analysis and found to be $0.1 \mathrm{pg} / \mathrm{mL}$ and $10 \mathrm{ng} / \mathrm{mL}$, respectively. It is presumed that the uniformly distributed gold nanoparticles on the hemispheric array increased the surface area of the electrode so that an increased number of MUA molecules could attach to the electrode, thereby increasing the sequential binding of EDC/NHS and IgG molecules. Hence the effective binding between Der $\mathrm{p} 2$ and IgG could be enhanced, resulting in sensitivity of the sensor being enhanced considerably. Fluorescence analysis results obtained using enhanced green fluorescent protein further indicate that the high sensitivity of the proposed polycarbonate-based nanobiosensor can be attributed to the intensity and uniformity of the gold nanoparticles on the sensor. The proposed low-cost and high sensitivity sensor could be useful for the rapid detection of rare molecules in an analyte.

In future work, the polycarbonate-based biosensor will be integrated into the conventional printed circuit board fabrication process to produce a final product. Mass production tasks will be conducted. A portable electrochemical impedance spectroscopy device is currently being designed and fabricated for fast and low-cost detection.

\section{Acknowledgments}

The authors would like to thank the Department of Health and the National Science Council of Taiwan for their financial support of this research under grant numbers DOH100-TDN-111-006 and NSC99-2622-E-005-007-CC3.

\section{Disclosure}

The authors report no conflicts of interest in this work.

\section{References}

1. Sia SK, Kricka LJ. Microfluidics and point-of-care testing. Lab Chip. 2008;8:1982-1983.

2. Chin CD, Linder V, Sia SK. Lab-on-a-chip devices for global health: past studies and future opportunities. Lab Chip. 2007;7:41-57.

3. Yager P, Edwards T, Fu E, et al. Microfluidic diagnostic technologies for global public health. Nature. 2006;442:412-418.

4. Lim YC, Kouzani AZ, Duan W. Lab-on-a-chip: a component view. Microsyst Technol. 2010;16:1995-2015.
5. Haeberle S, Zengerle R. Microfluidic platforms for lab-on-a chip applications. Lab Chip. 2007;7:1094-1110.

6. Crevillen AG, Pumera M, Gonzalez MC, Escarpa A. Towards lab-ona-chip approaches in real analytical domains based on microfluidic chips/electrochemical multi-walled carbon nanotube platforms. Lab Chip. 2009;9:346-353.

7. Lee YF, Lien KY, Lei HY, Lee GB. An integrated microfluidic system for rapid diagnosis of dengue virus infection. Biosens Bioelectron. 2009;25:745-752.

8. Martinez AW, Phillips ST, Butte MJ, Whitesides GM. Patterned paper as a platform for inexpensive, low volume, portable bioassays. Angew Chem Int Ed. 2007;46:1318-1320.

9. Martinez AW, Phillips ST, Carrilho E, Thomas SW III, Sindi H, Whitesides GM. Simple telemedicine for developing regions: camera phones and paper-based microfluidic devices for real-time, off-site diagnosis. Anal Chem. 2008;80:3699-3707.

10. Martinez AW, Phillips ST, Carrilho E, Whitesides GM. Diagnostics for the developing world: microfluidic paper-based analytical devices. Anal Chem. 2010;82:3-10.

11. Martinez AW, Phillips ST, Wiley BJ, Gupta M, Whitesides GM. FLASH: A rapid method for prototyping paper-based microfluidic devices. Lab Chip. 2008;8:2146-2150.

12. Bruzewicz DA, Reches M, Whitesides GM. Low-cost printing of poly (dimethylsiloxane) barriers to define microchannels in paper. Anal Chem. 2008;80:3387-3392.

13. Abe K, Suzuki K, Citterio D. Inkjet-printing microfluidic multianalyte chemical sensing paper. Anal Chem. 2008;80:6928-6934.

14. Li X, Tian J, Garnier G, Shen W. Fabrication of paper-based microfluidic sensors by printing. Colloids Surf B Biointerfaces. 2010;76:564-570.

15. Lu Y, Shi W, Qin J, Lin B. Fabrication and characterization of paperbased microfluidics prepared in nitrocellulose membrane by wax printing. Anal Chem. 2010;82:329-335.

16. Carrilho E, Martinez AW, Whitesides GM. Understanding wax printing: a simple micropatterning process for paper-based microfluidics. Anal Chem. 2009;81:7091-7095.

17. Carrilho E, Phillips ST, Vella SJ, Martinez AW, Whitesides GM. Diagnostics for the developing world: microfluidic paper-based analytical devices. Anal Chem. 2009;81:5990-5998.

18. Dungchai W, Chailapakul O, Henry CS. Electrochemical detection for paper-based microfluidics. Anal Chem. 2009;81:5821-5826.

19. Nie Z, Nijhuis CA, Gong J, et al. Electrochemical sensing in paper-based microfluidic devices. Lab Chip. 2010;10:477-483.

20. Nie Z, Deiss F, Liu X, Akbulut O, Whitesides GM. Integration of paperbased microfluidic devices with commercial electrochemical readers. Lab Chip. 2010;10:3163-3169.

21. Delaney JL, Hogan CF, Tian J, Shen W. Electrogenerated chemiluminescence detection in paper-based microfluidic sensors. Anal Chem. 2011;83:1300-1306.

22. Drummond TG, Hill MG, Barton JK. Electrochemical DNA sensors. Nat Biotechnol. 2003;21:1192-1199.

23. Wang Y, Li C, Li X, Li Y, Kraatz HB. Unlabeled hairpin-DNA probe for the detection of single-nucleotide mismatches by electrochemical impedance spectroscopy. Anal Chem. 2008;80:2255-2260.

24. Kafka J, Pänke O, Abendroth B, Lisdat F. A label-free DNA sensor based on impedance spectroscopy. Electrochim Acta. 2008;53:7467-7474.

25. Huang J, Yang G, Meng W, Wu L, Zhu A, Jiao X. An electrochemical impedimetric immunosensor for label-free detection of Campylobacter jejuni in diarrhea patients' stool based on O-carboxymethylchitosan surface modified $\mathrm{Fe}_{3} \mathrm{O}_{4}$ nanoparticles. Biosens Bioelectron. 2009;40: 893-896.

26. Tsai JJ, Bau IJ, Chen HT, Lin YT, Wang GJ. A novel nanostructured biosensor for the detection of the dust mite antigen Der p2. Int $J$ Nanomedicine. 2011;6:1-8.

27. Ensafi AA, Taei M, Rahmani HR, Khayamian T. Sensitive DNA impedance biosensor for detection of cancer, chronic lymphocytic leukemia, based on gold nanoparticles/gold modified electrode. Electrochim Acta. 2011;56:8176-8183. 
28. Lee PC, Meisel DJ. Adsorption and surface-enhanced Raman of dyes on silver and gold sols. J Phys Chem. 1982;86:3391-3395.

29. Hrapovic S, Liu Y, Male KB, Luong JHT. Electrochemical biosensing platforms using platinum nanoparticles and carbon nanotubes. Anal Chem. 2004;76:1083-1088.

30. Osterlund C, Gronlund H, Polovic N, Sundstrom S, Gafvelin G, Bucht A. The non-proteolytic house dust mite allergen Der $\mathrm{p} 2$ induce NF-KB and MAPK dependent activation of bronchial epithelial cells. Clin Exp Allergy. 2009;39:1199-1208.
31. Tsai JJ, Shen HD, Chua KY. Purification of group 2 Dermatophagoides pteronyssinus allergen and prevalence of its specific IgE in asthmatics. Int Arch Allergy Immunol. 2000;121:205-210.

\section{Publish your work in this journal}

The International Journal of Nanomedicine is an international, peerreviewed journal focusing on the application of nanotechnology in diagnostics, therapeutics, and drug delivery systems throughout the biomedical field. This journal is indexed on PubMed Central, MedLine, CAS, SciSearch ${ }^{\circledR}$, Current Contents ${ }^{\circledR} /$ Clinical Medicine,
Journal Citation Reports/Science Edition, EMBase, Scopus and the Elsevier Bibliographic databases. The manuscript management system is completely online and includes a very quick and fair peer-review system, which is all easy to use. Visit http://www.dovepress.com/ testimonials.php to read real quotes from published authors.

Submit your manuscript here: http://www.dovepress.com/international-journal-of-nanomedicine-journal 